\title{
Interactions between wheat, rye and Aegilops ventricosa chromosomes on homologous and homoeologous pairing
}

\author{
N. Cuñado, \\ M. C. Cermeño and \\ J. Orellana
}

\author{
Departamento de Genética, \\ Facultad de Biología, \\ Universidad Complutense, \\ 28040-Madrid, Spain.
}

Different wheat-rye, Ae. ventricosa-rye and wheat-ventricosa-rye genome combinations were analysed at meiosis. In all cases it was possible to estimate the frequencies of the different types of homologous and homoeologous pairing, by using a C-banding technique. Rye homologous pairing decreased in the presence of wheat and Ae. ventricosa genomes with respect to that observed in diploid rye. However, the frequencies of all types of homoeologous pairing were very constant in all hybrids analysed and independent of the number of genomes which were present in the hybrids.

\section{INTRODUCTION}

The mutual influence between wheat and rye genomes on meiotic pairing has been reported in many wheat-rye combinations (see Naranjo et al., 1979). Wheat chromosomes seem to produce a decrease of homologous pairing between rye chromosomes (Lacadena, 1967; Lelley, 1976), whereas the homoeologous pairing between wheat chromosomes increases when the dosage of rye genomes increases (Miller and Riley, 1972; Naranjo et al., 1979).

Although most of these types of studies have been usually limited to wheat and rye chromosomes, there is some evidence for assuming similar interactions between Aegilops and rye chromosomes. Thus, in Ae. ventricosa-Secale cereale amphiploid plants it has been reported that a decrease of meiotic pairing either for rye and Aegilops chromosomes occurs with respect to that observed in their parental species (Cermeño et al., 1985).

The aim of this work was to analyse the mode in which Aegilops ventricosa, rye and wheat genomes interact in different combinations.

\section{MATERIAL AND METHODS}

The materials used for this work were as follows:

Five plants of diploid rye Secale cereale (genome constitution RR) cv. La Raña, taken from Logrosan, Cáceres (Spain) (Orellana and Giraldez, 1981).

Five plants of the synthetic amphiploid Aegilops ventricosa-Secale cereale (genome constitution DDUnUnRR) kindly supplied by $\mathrm{Dr} F$. Dosba, Plant Breeding Stn., Res. Center of Rennes, INRA (France). The designation of $\mathrm{M}^{\mathrm{v}}$ genome of $A e$. ventricosa has been changed for Un according to the new nomenclature proposed by Kimber et al. (1983).

Five plants of the first backcross obtained from the crosses between the amphiploid Ae. ventricosa$S$. cereale and diploid rye cv. Dakold (genome constitution DUnRR).

Four triticale $\times$ rye hybrid plants (genome constitution ABRR) obtained from the crosses between hexaploid triticale cv. Cachirulo (genome constitution AABBRR) and diploid rye (RR), line E (Orellana and Giraldez, 1984).

Two trigeneric hybrid plants (genome constitution ABDUnRR) obtained from the crosses between hexaploid triticale cv. Cachirulo and $A e$. ventricosa-S. cereale amphiploid plants.

In order to obtain meiotic cells, anthers were fixed in acetic ethanol $1: 3$ and stored following the Giemsa C-banding technique described previously (Giraldez et al., 1979).

\section{RESULTS}

The C-banding technique makes it possible to distinguish the rye genome from the Aegilops 
ventricosa as well as the wheat genomes in all hybrids analysed since rye shows telomeric Cblocks in most of its chromosomes whereas Ae. ventricosa and wheat possess intercalary and dispersed C-heterochromatin in some of their chromosomes (figs. 1-2). In addition, in Ae. ventricosa two chromosome groups may be differentiated according to their C-banding pattern, i.e., 16 chromosomes with prominent Cheterochromatin located at centromeric and pericentromeric regions and 12 almost entirely euchromatic (fig. 1). These differences could represent the Un ( $\mathrm{M}^{\mathrm{v}}$ in previous works) and $\mathrm{D}$ genomes, respectively, although obviously, at least one of the heterochromatic chromosomes should belong to the $\mathrm{D}$ genome. In previous work (Cermeño et al., 1985) this chromosome could be distinguished from those of the Un genome in Ae. ventricosa and Ae. ventricosa-S. cereale amphiploid plants due to the high degree of meiotic regularity observed for Ae. ventricosa chromosomes. By contrast, in this work only the two groups mentioned above can be accurately distinguished since the heterochromatic chromosome of the D genome is not identifiable when it is involved in bivalents in which homoeologous pairing takes place.

Similarly, in Triticum turgidum, which is used for making hexaploid triticale, two groups can be distinguished: 14 chromosomes without prominent $\mathrm{C}$-heterochromatin and the other 14 with scattered and dispersed C-heterochromatin (fig. 2). These two groups represent the A and B genomes, respectively (see Gill and Kimber, 1974).

These different C-banding patterns has allowed us to estimate the frequencies of homologous and homoeologous pairing at meiosis in all the hybrids analysed.

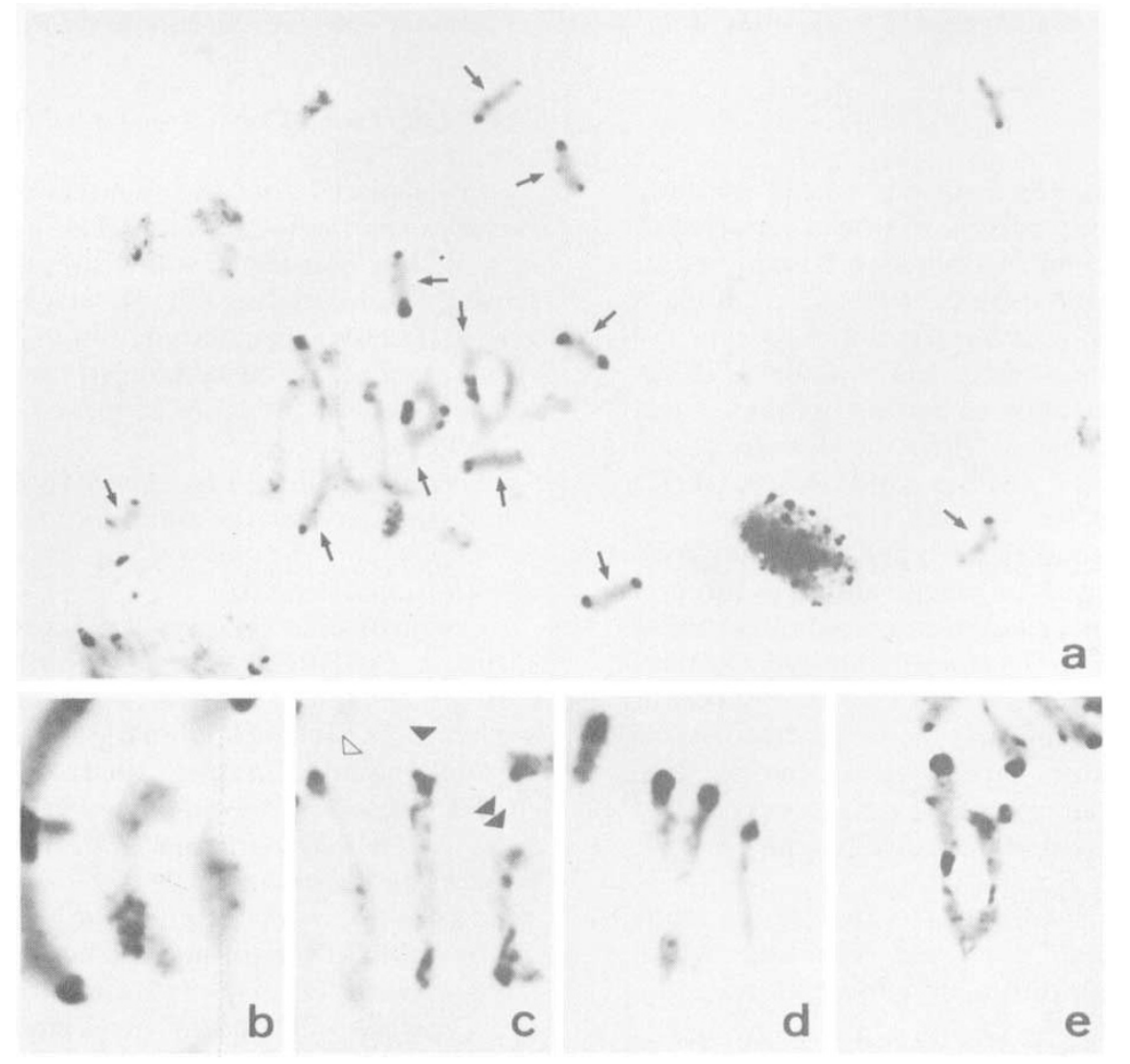

Figure 1 Meiosis in DUnRR hybrid plants. (a) C-banded metaphase I cell (arrows indicate rye bivalents and univalents). (b) Homoeologous pairing between euchromatic and heterochromatic (eu-het) chromosomes of Ae. ventricosa. (c) Three bivalents formed by: one chromosome of rye and one euchromatic chromosome (R-eu) of Ae. ventricosa (open triangle), two heterochromatic chromosomes (het-het) of Ae. ventricosa (black triangle) and euchromatic and heterochromatic (eu-het) chromosomes of Ae. ventricosa (double triangle). (d) V-shaped trivalent formed by Ae. ventricosa chromosomes (het-eu-het). (e) V-shaped rye-ventricosa trivalent ( $R-R-h e t)$. 


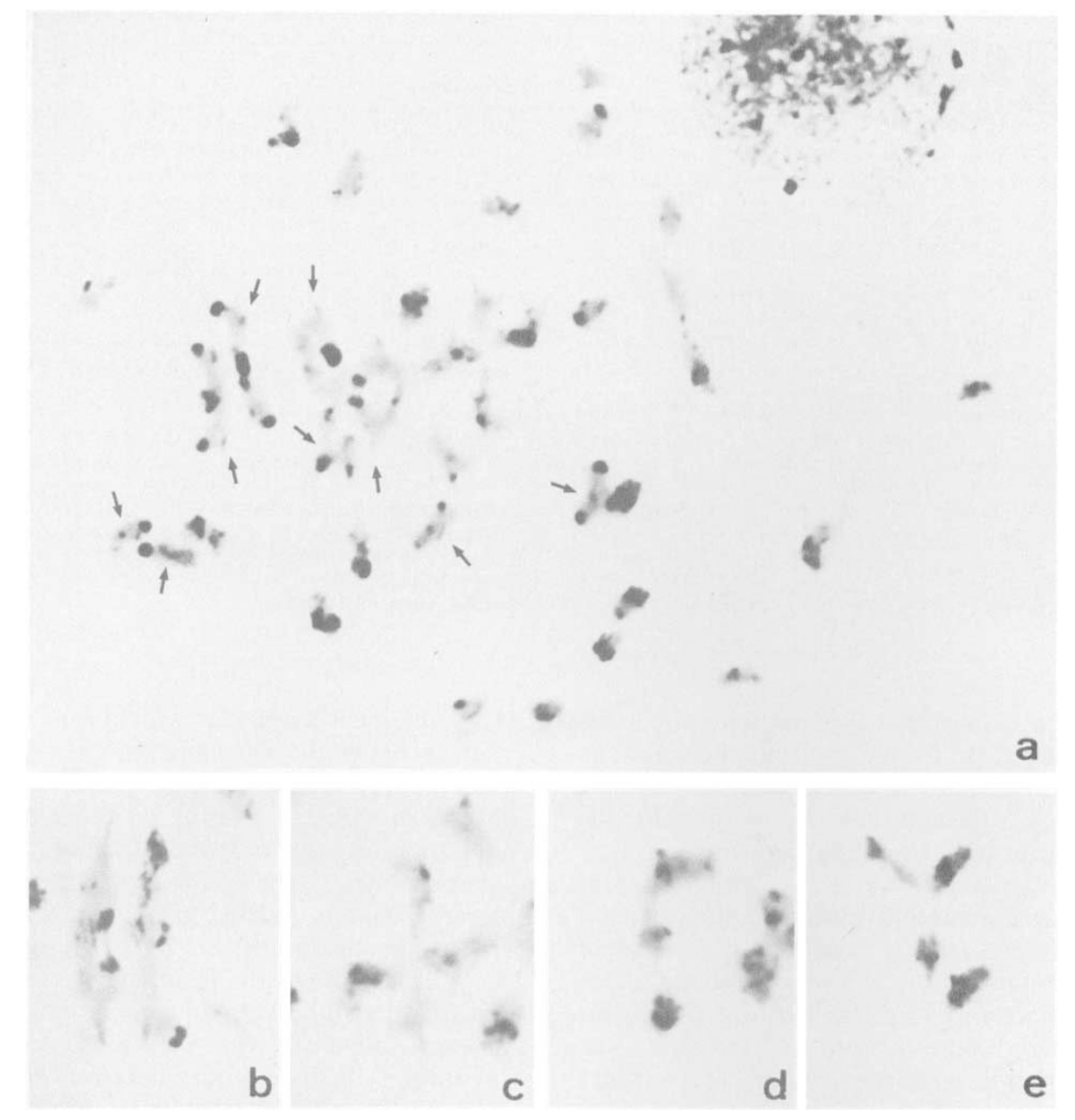

Figure 2 Meiosis in ABDUnRR hybrid plants. (a) C-banded metaphase I cell (arrows indicate rye bivalents and univalents). (b) A bivalent formed by one chromosome of rye and one heterochromatic chromosome (R-het). (c) Homoeologous pairing between two eucharomatic (eu-eu) chromosomes. (d) A bivalent formed between one heterochromatic and one euchromatic (het-eu) homoeologous chromosomes. (e) V-shaped trivalent formed between ventricosa and wheat chromosomes.

\section{(i) Homologous pairing}

Although in the diploid rye there was a high degree of meiotic regularity, in all amphiploid and hybrid plants in the present study it was possible to detect a considerable degree of irregularities affecting rye chromosomes, leading to a decrease of rye homologous pairing.

The frequencies of univalents and open bivalents increased in the hybrid plants but they did not follow a fixed pattern since except for ABRR hybrids, a between plants heterogeneity within each genome constitution was found (table 1).

As it has been pointed out by Cermeño et al. (1985) the mere hybridisation and chromosome doubling between Ae. ventricosa and S. cereale produces a decrease of homologous pairing in the genomes of both parental species in the amphiploid. However, in the present study it is worth mentioning that rye homologous pairing was always lower in Ae. ventricosa-rye combinations than in triticale-rye hybrids (table 1).

\section{(ii) Homoeologous pairing}

In hexaploid triticale as well as in the amphiploid Ae. ventricosa-S.cereale there are certain meiotic irregularities but meiotic pairing always occurs between homologous chromosomes (see Gupta and Priyadarshan, 1982; Cermeño et al., 1985). 


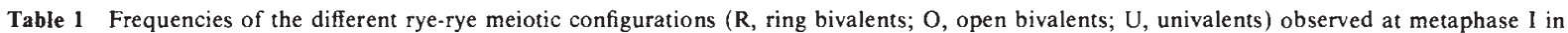
all plants analysed. The comparisons between the mean number of bound arms per cell in each type of plants is also included

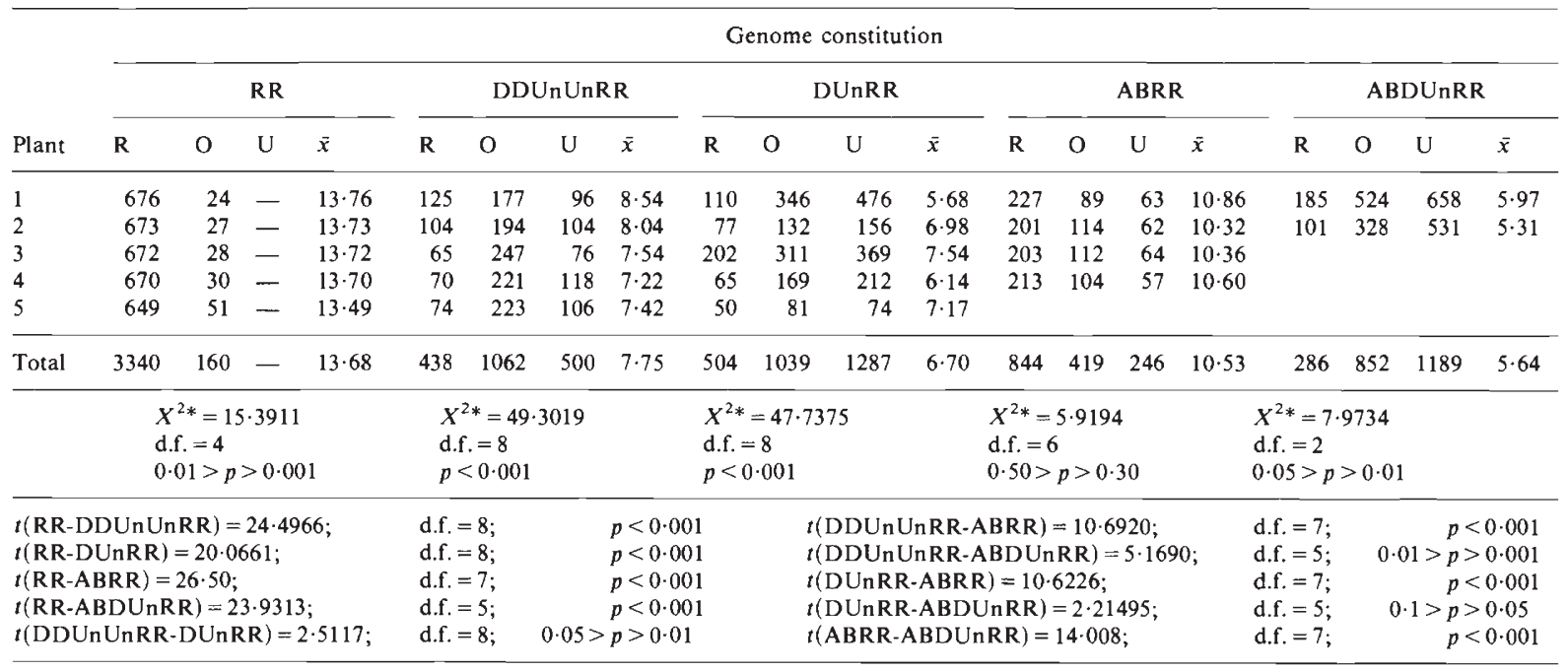

* Contingency tests were performed with the number of univalent pairs

Probably the simplest explanation for this behaviour would be to assume that the affinities for pairing between the homologous chromosomes should be very high and therefore homoeologous pairing opportunities would be very low.

However, in the hybrids in which several genomes are in the haploid condition, the situation could be different. In this case each chromosome is not accompanied by a homologue and consequently the competition for pairing can occur between homoeologous chromosomes.

In the hybrids with the genome constitution DUnRR four types of homoeologous associations were distinguished at metaphase I, namely, ventricosa-rye associations in which one euchromatic chromosome of $A$ e. ventricosa was involved (R-eu) (fig. 1c); ventricosa-rye associations in which one heterochromatic chromosome of Ae. ventricosa was involved (R-het) (fig. 1e); ventricosa-ventricosa homoeologous pairing formed between heterochromatic and euchromatic chromosomes (het-eu) (figs. 1b-c) and ventricosa-ventricosa homoeologous pairing between two heterochromatic chromosomes (het-het) (fig. 1c).

Table 2 shows the frequencies of such types of pairing. In all plants, the frequencies of R-het and $\mathrm{R}$-eu associations were very low, probably due to evolutionary divergences between ventricosa and rye chromosomes. However, as expected, the frequencies of homoeologously paired bound arms between ventricosa chromosomes were higher.

Table 2 Frequencies of the different meiotic configurations ( $R$, ring bivalents; $O$, open bivalents and trivalents) formed between homoeologous chromosomes in DUnRR hybrids

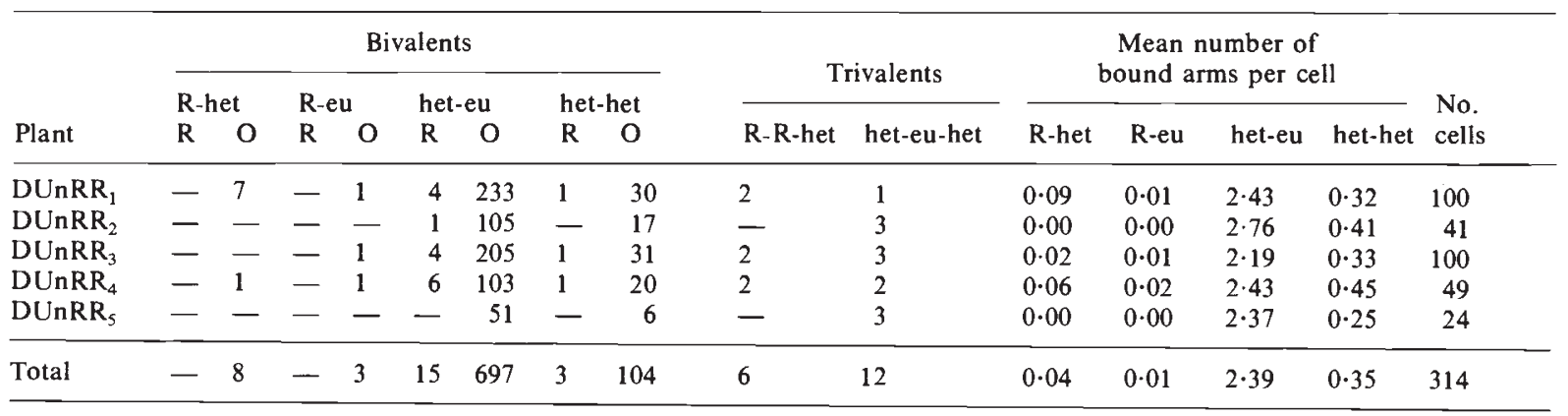

* All trivalents were V-shaped

$(\mathrm{R})=$ rye genome

(het) = heterochromatic chromosome

(eu) = euchromatic chromosome 
A maximum of only one bivalent per cell between heterochromatic chromosomes was found. Moreover, no bivalent between euchromatic chromosomes was observed. These results indicate that the two groups of chromosomes (with C-heterochromatin and without C-heterochromatin) actually represent the $U n$ and $D$ genomes, respectively, and that non-homologous or non-homoeologous associations do not exist in our material.

As is shown in table 2 the frequency of homoeologous pairing between the heterochromatic chromosome pair was similar to that of the remaining six homoeologous pairs.

Now, if these six pairs of homoeologous have the same probability for pairing and if meiotic pairing is at random, the distribution of paired arms per cell should follow the binomial series. However, the observed and expected were very different when the comparison was performed (table 3 ). These results seem to indicate that the probabilities for pairing could be different for each homoeologous group.

On the other hand, if homoeologous pairing between rye and ventricosa occurs in DUnRR hybrids, trivalents and quadrivalents are expected (see table 2) (fig. 1e). Nevertheless trivalents involving only ventricosa chromosomes could not be explained simply by homoeologous pairing. In our material a maximum number of one trivalent per cell involving ventricosa chromosomes was found. This was always formed by two heterochromatic and one euchromatic chromosomes. The trivalents were always V-shaped, the euchromatic chromosome being located at the vertex of the $\mathrm{V}$ configuration (fig. 1d). This persistent disposition leads to the assumption of the existence of an interchange (translocation) between the D and Un genomes. Similar systems of differentiation among
Table 3 Comparison between the number of homoeologous associations per cell involving heterochromatic and euchromatic (het-eu) ventricosa chromosomes observed at metaphase I and the expected on the basis of a binomial distribution

\begin{tabular}{|c|c|c|c|c|c|c|c|}
\hline \multicolumn{7}{|c|}{ No. bound arms per cell } & \multirow{2}{*}{$\begin{array}{l}6 \text { or } \\
\text { more }\end{array}$} \\
\hline & 0 & 1 & 2 & 3 & 4 & 5 & \\
\hline Obs. & 4 & 39 & 132 & 114 & & 4 & \\
\hline Exp. & $17 \cdot 78$ & $57 \cdot 68$ & $85 \cdot 76$ & $77 \cdot 27$ & $47 \cdot 00$ & $20 \cdot 33$ & $8 \cdot 17$ \\
\hline
\end{tabular}

$X^{2}=94 \cdot 00 ;$ d.f. $=5 ; p<0.001$

related genomes have been reported from isozyme studies in Triticum (Kobrehel and Feillet, 1975; Benito and Perez de la Vega, 1979; Salinas and Benito, 1984), Agropyron (Kobrehel, 1977) and Hordeum (Benito et al., 1985).

Table 4 shows the wheat-wheat and wheat-rye homoeologous pairing frequencies in the ABRR hybrids studied. The levels of homoeologous pairing were not very different between wheat-wheat and ventricosa-ventricosa or between wheat-rye and ventricosa-rye in the DUnRR and ABRR hybrids (see table 6).

In the trigeneric hybrid ABDUnRR, several types of homoeologous pairing could be also identified at metaphase I: homoeologous associations formed between rye and wheat or rye and ventricosa heterochromatic (R-het) (fig. 2b) or euchromatic (R-eu) (fig. 2e) chromosomes; and homoeologous pairing involved only wheat or ventricosa heterochromatic (het-het), euchromatic (eu-eu) (fig. 2c) or chromosomes with different heterochromatin constitution (het-eu) (fig. 2d). In these hybrids it was impossible to discern if the pairing observed was due to wheat or to ventricosa chromosomes because the C-banding patierns of $\mathrm{A}$ and $\mathrm{B}$ genomes were very similar to those of $\mathrm{D}$ and Un genomes, respectively.

Table 4 Frequencies of the different meiotic configurations ( $R$, ring bivalents; $O$, open bivalents and trivalents) formed between homoeologous chromosomes in ABRR hybrids (taken from Orellana and Giraldez, 1984)

\begin{tabular}{|c|c|c|c|c|c|c|c|c|}
\hline \multirow[b]{2}{*}{ Plant } & \multicolumn{4}{|c|}{ Bivalents } & \multirow[b]{2}{*}{$\begin{array}{l}\text { Trivalents } \\
\text { wheat-rye* }\end{array}$} & \multicolumn{2}{|c|}{$\begin{array}{l}\text { Homoeologous } \\
\text { associations/cell }\end{array}$} & \multirow[b]{2}{*}{ No. cells } \\
\hline & \multicolumn{2}{|c|}{ wheat-rye } & \multicolumn{2}{|c|}{ wheat-wheat } & & wheat-rye & wheat-wheat & \\
\hline $\mathrm{ABRR}_{1}$ & - & 3 & 21 & 115 & 1 & 0.08 & $3 \cdot 61$ & 50 \\
\hline $\mathrm{ABRR}_{2}$ & - & 3 & 21 & 104 & 3 & $0 \cdot 12$ & $2 \cdot 98$ & 50 \\
\hline $\mathrm{ABRR}_{3}$ & - & 1 & 14 & 105 & 3 & 0.08 & $2 \cdot 72$ & 50 \\
\hline $\mathrm{ABRR}_{4}$ & - & 5 & 26 & 110 & 2 & $0 \cdot 14$ & $3 \cdot 28$ & 50 \\
\hline Total & - & 12 & 82 & 434 & 9 & $0 \cdot 105$ & $3 \cdot 15$ & 200 \\
\hline
\end{tabular}

* All trivalents observed were V-shaped trivalents 
Table 5 shows the frequencies of the different meiotic configurations observed in these hybrids as well as the total frequencies of the types of homoeologous pairing mentioned above.

In the hybrids ABDUnRR the possibilities for establishing homoeologous pairing are, in principle, higher than in DUnRR or ABRR hybrids, because the first possesses two additional genomes, however no clear increase of any type of pairing was observed (see table 6).

\section{DISCUSSION}

\section{Homologous pairing}

In all amphiploids and hybrids studied here, ryerye homologous pairing decreased in respect to that observed in diploid rye. This seemed to be due to the presence of the Aegilops and wheat genomes. The effect seemed to be higher when rye and Aegilops chromosomes were combined (table 1).

It has been reported that wheat chromosomes produce a decrease in homologous pairing between rye chromosomes (Lacadena, 1967; Lelley, 1976). Our results are in agreement with this assumption. However the reduction of the dosage of wheat and Aegilops genomes in wheat-rye and ventricosa-rye combinations does not seem to increase the probability of homologous pairing between rye chromosomes in disagreement with Miller and Riley (1972). At least in the first backcross hybrids ABRR and DUnRR the dosage of wheat and ventricosa genomes have been reduced with respect to the parental amphiploids (AABBRR, DDUnUnRR), and however the rye-rye homologous pairing is lower than in those amphiploids (table 1) (see Naranjo and Lacadena, 1982; Cermeño et al., 1985).

Thomas and Kaltsikes $(1974 ; 1976)$ and Roupakias and Kaltsikes (1977) concluded that the presence of telomeric C-heterochromatin on rye chromosomes could be responsible for the rye meiotic irregularities observed in triticale and wheat-rye combinations, since heterochromatin is late replicating and therefore DNA replication of $\mathrm{C}$-heterochromatin could interfere with meiotic prophase pairing. Nevertheless, this cannot explain our results because if the only cause of the decrease of the rye homologous pairing was the presence of telomeric C-blocks in the rye chromosomes, we would expect the same behaviour in the amphiploids as in the hybrids, and in the $A e$. ventricosa-rye as in the wheat-rye hybrids. However the results are very different (table 1) in spite of the fact that the C-banding patterns for the rye chromosomes are very similar in all the amphiploids and hybrids.

Genetical differences between the rye cultivars used for obtaining the hybrids might explain different levels of rye homologous pairing detected. However if this is so, the rye system seems to be only operative in the wheat-rye and Ae. ventricosarye hybrids since intraspecific rye hybrids generally show similar levels of pairing (see Orellana et al., 1984).

Table 5 Frequencies of the different meiotic configurations ( $R$, ring bivalents; $O$, open bivalents and multivalents) formed between homoeologous chromosomes in ABDUnRR hybrids

\begin{tabular}{|c|c|c|c|c|c|c|c|c|c|c|c|c|c|c|c|c|c|}
\hline \multirow[b]{3}{*}{ Plant } & \multicolumn{10}{|c|}{ Bivalents } & \multirow{2}{*}{\multicolumn{7}{|c|}{ Trivalents* }} \\
\hline & \multicolumn{2}{|c|}{ R-het } & \multicolumn{2}{|c|}{ R-eu } & \multicolumn{2}{|c|}{ het-eu } & \multicolumn{2}{|c|}{ het-het } & \multicolumn{2}{|c|}{ eu-eu } & & & & & & & \\
\hline & $\mathrm{R}$ & 0 & $\mathrm{R}$ & $\mathrm{O}$ & $\mathbf{R}$ & 0 & $\mathbf{R}$ & 0 & $\mathrm{R}$ & 0 & R-R-eu & R-R-het & R-eu-het & R-het-eu & het-eu-het & het-het-eu & het-eu-eu \\
\hline $\mathrm{ABDUnRR}_{2}$ & - & 6 & - & 2 & 3 & 92 & 1 & 43 & 1 & 22 & - & 1 & - & 1 & 1 & - & 2 \\
\hline Total & - & 12 & - & 12 & 12 & 307 & 5 & 135 & 3 & 75 & 1 & 2 & 2 & 1 & 9 & 1 & 6 \\
\hline
\end{tabular}

\begin{tabular}{|c|c|c|c|c|c|c|c|}
\hline & \multirow{2}{*}{$\frac{\text { Quadrivalents } \dagger}{\text { R-R-eu-eu }}$} & \multicolumn{5}{|c|}{ Homoeologous associations per cell } & \multirow[b]{2}{*}{ No. cell } \\
\hline & & R-het & R-eu & het-eu & het-het & eu-eu & \\
\hline$A B D U n R_{1}$ & 1 & 0.05 & 0.09 & $1 \cdot 71$ & 0.67 & 0.41 & 150 \\
\hline$A B D U n R R_{2}$ & - & 0.08 & $0 \cdot 02$ & $1 \cdot 03$ & 0.45 & $0 \cdot 26$ & 100 \\
\hline Total & 1 & $0-065$ & $0 \cdot 06$ & $1 \cdot 37$ & 0.56 & $0 \cdot 34$ & 250 \\
\hline
\end{tabular}

* All trivalents were V-shaped

$\dagger$ All quadrivalents were chain quadrivalents

(R): rye genome

(het): heterochromatic chromosome

(eu): euchromatic chromosome 
Table 6 Homoeologous pairing frequencies per cell in all hybrids analysed. The comparisons of the total homoeologous pairing frequencies among the three type of hybrid plants are also included

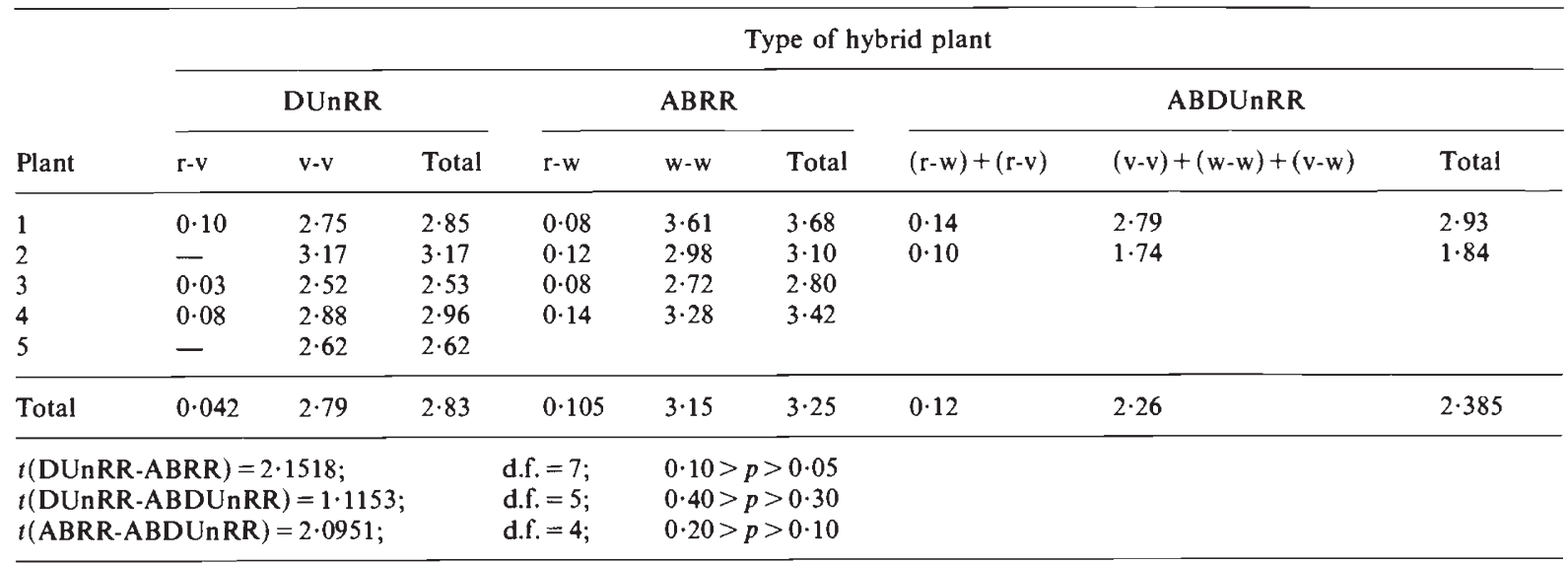

(r) rye chromosome

(v) ventricosa chromosome

(w) wheat chromosome

Probably the mere combination of rye and any other alien genome can produce genetic interactions responsible for the decrease of rye homologous pairing. These types of interactions also occurs for wheat and Aegilops chromosomes. Thus, the addition of any rye or Ae. umbellulata chromosome to wheat produces a decrease of wheat-wheat homologous pairing (Orellana et al., 1984; Cuñado, in preparation).

\section{Homoeologous chromosome pairing}

As described above, rye chromosomes show different levels of homologous pairing in each type of plants. However the total amount of homoeologous pairing is very similar in all hybrids (table 6). The similarities can also be observed for each specific type of homoeologous pairing formed between rye, ventricosa and wheat chromosomes (see tables 2, 4 and 5). The lack of relationship between homologous and homoeologous pairing might indicate the existence of a certain degree of independence among the genomes in relation to pairing.

In general, genetic control of meiosis is operative on the whole complement (see Riley and Law, 1965; Gale and Rees, 1970; Baker et al., 1976) but there are a few exceptions. Thus, chromosomespecific controls of chiasma formation have been reported in desynaptic mutants of Hipochoeris radicata (Parker, 1975) and Crepis capillaris (Tease and Jones, 1976) and recently a case of genomespecific control has been found by Orellana $e t$ al. (1985) in meiotic mutants of the amphiploid Ae. ventricosa-S. cereale. In this case, irregular meiotic behaviour was only limited to the Aegilops ventricosa chromosomes, which showed a high degree of asynapsis, whereas the rye chromosomes showed a normal behaviour. Similar results have been obtained in asynaptic individuals of Locusta migratoria and Schistocerca gregaria (Rees, 1957; John and Naylor, 1961) when the irregularities were limited to the longest and the shortest chromosomes of the complement, respectively.

It is reasonable to assume the existence of a general control which acts on the whole complement, but besides this control a genome-specific control on homoeologous pairing can occur. Although speculative, one can imagine that the homoeologous pairing control is essentially different from the homologous one, and therefore homoeologous pairing might be affected by factors which do not act on homologous pairing.

In the hybrids DUnRR and ABRR the values of ventricosa-ventricosa and wheat-wheat homoeologous pairing are similar. Therefore in the hybrid ABDUnRR double homoeologous pairing would be expected if the ventricosa-ventricosa and wheat-wheat types are independent. Obviously, ventricosa and wheat chromosomes can pair with each other as is demonstrated by the presence of euchromatic-euchromatic associations (fig. 2c) (pairing between A and D genomes) but even so, higher values of homoeologous pairing are expected than in the DUnRR or ABRR hybrids. However, similar or even slightly lower values were observed, although there was no significant deviation. This can only be explained by the existence of a control of a maximum level of homoeologous pairing. 
It has been reported that in wheat-rye combinations, homoeologous pairing between wheat chromosomes increases with increasing the dosage of the rye genomes (Miller and Riley, 1972; Naranjo et al., 1979). This behaviour has been explained in terms of an inhibition of the effect of a single dose of the $\mathrm{Ph}$ locus of chromosome 5B by two or more doses of chromosome 5R (Jouve et al., 1980), however Miller and Riley (1972) concluded that the promotion of homoeologous chromosome pairing by the rye genotypes might reside in the activities of the complete genome and not necessarily in the homoeologous group 5 chromosome.

More recent studies have demonstrated that chromosome 5R affects wheat homologous pairing in wheat-rye addition lines but it is also true that any other rye addition produces a decrease of homologous pairing, though in this case the effect is lower (Orellana et al., 1984). Moreover it seems clear that rye genomes may modulate the wheat homologous and homoeologous pairing in wheatrye combinations and probably also in ventricosarye combinations, but the mode in which this control acts is unknown and further studies combining genomes in different doses are required.

\section{REFERENCES}

BAKER, B. S., CARPENTER, A. T. C., ESPOSITO, M. S., ESPOSITO, R. E. AND SANDLER, L. 1976. The genetic control of meiosis. Ann. Rev. Genet., 10, 53-134.

BENITO, C., FIGUEIRAS, A. M., GONZALEZ-JAEN, M. T. AND SALINAS, J. 1985. Biochemical evidence of homoeology between wheat and barley chromosomes. Z. Pflanzenzuchtg., 94, 307-320.

BENITO, C. AND PEREZ DE LA VEGA, M. 1979. The chromosomal location of peroxidase isozymes of the wheat kernel. Theor. Appl. Genet., 55, 73-76.

CERMEÑo, M. C., CUÑAdO, N. AND ORELlANA, J. 1985. Meiotic behaviour of Un, D and R genomes in the amphiploid Aegilops ventricosa-Secale cereale and its parental species. Theor. Appl. Genet., 70, 679-683.

GALE, M. D. AND REES, H. 1970. Genes controlling chiasma frequency in Hordeum. Heredity, 25, 393-410.

GILL, B. S. AND KIMBER, G. 1974. Giemsa C-banding and the evolution of wheat. Proc. Nat. Acad. Sci., 71, 4086-4090.

GiRAlDEZ, R., CERMEÑo, M. C. AND ORELlANA, J. 1979. Comparison of $\mathrm{C}$-banding pattern in the chromosomes of imbred lines and open pollinated varieties of rye (Secale cereale). Z. Pflanzenzuchtg., 83, 40-48.

GUPTA, P. K. AND PRIYADARShAN, P. M. 1982. Triticale: Present status and future prospects. Adv. Genet., 21, 255-345.

JOHN, B. AND NAYLOR, B. 1961. Anomalous chromosome behaviour in the germ line of Schistocerca gregaria. Heredity, 16, 187-198.
JOUVE, N., DIEZ, N. AND RODRIGUEZ, H. 1980. C-banding in $6 \times$-Triticale $\times$ Secale cereale L. Hybrid cytogenetics. Theor. Appl. Genet, 57, 75-79.

KIMBER, G., PIGNONE, D. AND SALLEE, P. J. 1983. The relationships of the $\mathrm{M}$ and $\mathrm{M}^{\mathrm{u}}$ genomes of Triticum. Can. J. Genet. Cytol. 25, 509-512.

KOBREHEL, K. 1977. Identification of chromosome segments controlling the synthesis of peroxidases in wheat seeds and in transfer lines with Agropyron elongatum. Can. J. Bot., 56, 1091-10.94.

KOBREHEL, K. AND FEILlET, P. 1975. Identification of genomes and chromosomes involved in peroxidase synthesis of wheat seeds. Can. J. Bot., 53, 2336-2344.

LACADENA, J. R. 1967. Alloplasmic rye. Cytogenetic considerations about its obtention. Portug. Acta Biol. Ser. A-X, 1-2, 129-142.

LELLEY, T. 1976. Effect of nulli/tetrasomic combinations of wheat chromosomes on the pairing of rye chromosomes in triticale. Z. Pflanzenzuchtg., 77, 89-99.

MILLER, T. E. AND RILEY, R. 1972. Meiotic chromosome pairing in wheat-rye combinations. Genet. Iber., 24, 241-250.

NARANJO, T., LACADENA, J. R. AND GIRALDEZ, R. 1979. Interaction between wheat and rye genomes on homologous and homoeologous pairing. Z. Pflanzenzuchtg., 82, 289-305.

NARANJO, T. AND LACADENA, J. R. 1982. C-banding pattern and meiotic pairing in five rye chromosomes of hexaploid triticale. Theor. Appl. Genet., 61, 233-237.

ORELlanA, J., ALAMO, I. AND GiRALDEZ, R. 1984. Metaphase I bound arms and crossing-over frequency in rye. II. Inbred lines. Z. Pflanzenzuchtg., 93, 199-211.

ORELlANA, J., CERMEÑo, M. C. AND LACADENA, J. R. 1984. Meiotic pairing in wheat-rye addition and substitution lines. Can. J. Genet. Cytol., 26, 25-33.

orellanA, J., CUÑAdo, N. AND CERMEÑo, M. C. 1985. Genome-specific control at meiosis on Aegilops ventricosaSecale cereale amphiploid mutant plants. Theor. Appl. Genet., (in press).

ORELlANA, J. AND GiRAlDEZ, R. 1981. Metaphase I bound arms and crossing-over frequency in rye. I. Open pollinated varieties. Chromosoma, 84, 439-449.

ORELLANA, J. AND GIRALDEZ, R. 1984. Metaphase I bound arms and crossing-over frequency in rye. IV. Triticale-rye hybrids. Heredity, 52, 265-271.

PARKER, I. S. 1975. Chromosome-specific control of chiasma formation. Chromosoma, 49, 391-406.

REES, H. 1957. Distribution of chiasmata in an asynaptic locust. Nature, 180, 559.

RILEY, R. AND LAW, C. N. 1965. Genetic variation in chromosome pairing. Adv. Genet., 13, 57-114.

ROUPAKIAS, D. G. AND KALTSIKES, P. J. 1977. The effect of telomeric heterochromatin on chromosome pairing of hexaploid triticale. Can. J. Genet. Cytol., 19, 543-548.

SALINAS, J. AND BENITO, C. 1984. Chromosomal location of peroxidase structural genes in rye (Secale cereale $L$.$) . Z$. Pflanzenzuchtg., 93, 291-308.

TEASE, C. AND JONES, G. H. 1976. Chromosome specific control of chiasma formation in Crepis capillaris. Chromosoma, 57, 33-49.

THOMAS, J. B. AND KALTSIKES, P. J. 1974. A possible effect of heterochromatin on chromosome pairing. Proc. Nat. Acad. Sci., 71, 2787-2790.

THOMAS, J. B. AND KALTSIKES, P. J. 1976. The genomic origin of the unpaired chromosomes in triticale. Can. J. Genet. Cytol., 18, 687-700. 